\title{
Using a Learning Analytics Tool for Evaluation in Self-Regulated Learning
}

\author{
Ana Rodriguez Groba*, Borja Vázquez Barreiros ${ }^{\dagger}$, Manuel Lama ${ }^{\dagger}$, Adriana Gewerc* and Manuel Mucientes ${ }^{\dagger}$ \\ *Department of Didactic and School Organization \\ University of Santiago de Compostela, Spain \\ Email: ana.groba@usc.es, adriana.gewerc@usc.es \\ ${ }^{\dagger}$ Center for Research in Information Technologies (CiTIUS) \\ University of Santiago de Compostela, Spain \\ Email: borja.vazquez@usc.es, manuel.lama@usc.es, manuel.mucientes@usc.es
}

\begin{abstract}
In self-regulated learning, evaluation is a complex task of the teaching process, but even more if students have social media that allow them to build their personal learning environment in different ways. In these kind of virtual environments a large amount of data that needs to be assessed by teachers is generated, and therefore they require tools that facilitate the assessment task. In this paper, we present an experiment with a process mining-based learning analytics tool, called SoftLearn, that helps teachers to assess the student's activity in selfregulated learning. The subject of this experiment is taught in blended learning mode with weekly classroom sessions, and the students use a social network software, called ELGG, as an eportfolio in which they reflect their individual knowledge process construction. The results show that the use of this tool reduces significantly the assessment time and helps teachers to understand the learning process of the students.
\end{abstract}

\section{INTRODUCTION}

In the contemporary social and economic conditions it is imperative an education that goes beyond the boundaries of formal education, and enables the acquisition of skills that allow learning throughout life. The aim is a model that tries to make students active learners, actors and responsible for their learning [1]. In this context emerges the self-regulated learning, which is defined as an active and constructive process by which the student sets their own goals, trying to monitor, regulate and control their thoughts, their motivation and behavior according to those objectives [2]. Behavior, cognition, motivation and context are the areas that control the regulatory process and individuals (or students) need to select, study and create environments to optimize the learning behaviors that lead them to achieve their goals. Specifically, the self-regulated learning can be considered as a students' ability to establish the goals to be achieved and identify how to will reach them [3]. This ability is one of the main skills to be achieved in the university level, and distinguishes that level from others of the education system. The university education has to be responsible for providing the students with the necessary tools with which adapt to the changing society in which they live. This kind of activities can become social when activities are supported by others, or when students share tasks, perceptions, goals and strategies [4].

In this context, we present a learning approach that works through a personal learning environment (PLE), a social network and e-portfolios. PLEs consist of a set of tools, data sources, connections and activities commonly used by the student [5]. They are spaces characterized by personalization, ownership, interaction, dispersion, awareness, self-regulation and organizational involvement, and their use involves a methodology where students share and build processes that trigger their self-regulation [6]. Social networks have become a substantial support for the development of proposals that promote individual growth through the collective support [7], [8].

A proposal of formal learning that combines PLEs and social networks necessarily requires consistent evaluation processes. This is a key element in the quality of learning, conditioning its depth and level, because students can escape hardly from the effects of a poor teaching, but they cannot escape the effects of a poor assessment [9]. The e-portfolio becomes a teaching and evaluation methodology that appears as an alternative to those that are purely quantitative. It searches for the development of strategic and critical students and is consistent to support the development of self-regulatory behaviors. It is a collection of objects that can be shown as evidence of the learning process and the achievement of a student. It has a dual function: to collect and reflect the learning experiences and most meaningful achievements of a person (student, professional, worker, etc.) in a continuous way; and to inform clearly about the level of competence and other important experiences along their learning. According to Barrett [10], the portfolio is a comprehensive collection of the student's work that shows its efforts, progress and achievements.

However, in this learning context, a rigorous monitoring process generates such a volume of information that it becomes unmanageable: assessing a set of portfolios is much more complex than a simple note granting process [11]. In order to solve this problem, we need assessment tools based on the analysis of complex data that are stored when students participate in the PLE. This kind of tools, called learning analytics tools [12], can support the learning process as they provide customized information about student progress, allow us to investigate the traces of different users, and provide a way to track and record data, enhancing the assessment process [13]. Particularly, for student's assessment in self-regulated learning it is needed to discover the student's behavior from the activity registered in the PLEs. To achieve this goal, two different kinds of techniques have been proposed: sequential 
pattern mining (SPM) [14] and process mining (PM) [15].

On one hand, SPM techniques are mainly oriented to discover simple behavioral patterns that can occur during the set of learning activities carried out by learners, such as in self-regulated learning [16] or collaborative learning [17], [18]. Therefore, SPM is not appropriate for discovering learning paths that describe the whole process carried out by the learners during a course [18]. On the other hand, PM techniques have been applied to automatically discover the real workflow of learning activities that learners have undertaken. PM techniques achieve this objective by analyzing the events generated as consequence of the learner activity in the PLE. Some authors have applied PM to discover the processes followed by the learners in self-regulated learning [18], collaborative learning [19], [20], collaborative writing [21], and multiple-choice questions tests [22]. These works have two main drawbacks. The first one is that these techniques do not guarantee the completeness of the discovered learning path, i.e., they do not assure that all the activities undertaken by learners will be included in the learning path. The second drawback is that these works do not provide a graphical tool that enables teachers to visualize the real learning path of the course and to access easily to the learning content generated in the personal learning environment.

In this paper, we present a process mining-based tool, known as SoftLearn, which automatically discovers and represents the learning process followed by the students. SoftLearn guarantees that there are no missing activities in the student's learning process, enabling teachers to use it for student's assessment through its intuitive graphical interface. Furthermore, we have conducted an experiment where SoftLearn was used to assess the self-regulated learning process. As a result, SoftLearn reduces significantly the time needed for students' assessment and facilitates teachers to better understand the learning process followed by the students.

The paper is structured as follows: Section II describes the pedagogical scenario in which the SoftLearn tool has been applied; Section III presents the architecture of the SoftLearn tool; Section IV describes the experiment that was conducted to demonstrate the benefits of the SoftLearn tool; Section $\mathrm{V}$ discusses the main results of the experiment; and finally Section VI summarizes the main contributions of the paper.

\section{Pedagogical Scenario}

The results presented in this paper show an experiment in the subject Educational Technology of the Grade in Pedagogy at the Faculty of Education of the University of Santiago de Compostela. The subject uses the open source platform ELGG, which is an environment that integrates an individual space and also a social network with forums, blogs, microblogging, details of the user profile, friend lists, screen of activities, a personal wall, calendar, favorites and pages. The subject is developed in the form of blended learning with weekly classroom sessions where students discuss about the topics of the subject or undertake a practical exercise using a particular resource. This model seeks the development of learner's autonomy, a goal that is supported by a combination of classroom sessions and online contexts where the teacher is supporting the learning process [23].
We propose a methodology that is individual and in group at the same time, and that stimulates the development of selfregulated learning skills. The creation of student e-portfolios induces them to make a personal search showing how they have understood the concepts worked in the classroom sessions. Also, they incorporate into their PLE a blog post or a file reflecting their reflections as a result of the classes and readings. This work presents the process of each individual student, showing in the platform the progress in its knowledge. The students also make assignments in small groups in which they cooperate to achieve a shared product. Therefore, although the assignments are the minimum requirement for the subject, each student can follow their own path, selecting topics and resources that complement the training according to their own objectives.

This set of elements, which make up the personal environment, is evaluated by the teachers through a rubric. A rubric is an explicit set of criteria used for the evaluation of a particular type of work or activity, which provides more information than a simple note. This assessment is carried out during the process (midway through the course) and at the end. The assessment is qualitative, and it analyzes the text of blogs, microbloging, pages, etc., and requires the reading of hundreds of inputs to know if the student has achieved the expected competencies. The assessment of the student's behavior is extremely time consuming, given the number of students (72 in this course) and the amount of documents associated to each personal space. Table I shows the number of elements generated by the students during the entire course of Educational Technology.

TABLE I. SIZE OF THE STUDENTS' E-PORTFOLIOS IN THE SUBJECT EDUCATIONAL TECHNOLOGY.

\begin{tabular}{ll} 
Portfolio element & \#Elements \\
\hline \hline Blogs & 934 \\
Pages & 377 \\
Tweets & 891 \\
Comments & 1,097 \\
Bookmarks & 317 \\
Files & 894 \\
\hline
\end{tabular}

The time taken by this type of assessment for each student becomes an obstacle for teachers to integrate this type of pedagogical approach. On the other hand, the processes of selfregulated learning, whether social or individual, are hidden to the evidences. In order to solve these problems, we need a tool that helps to extract the information required to evaluate the learning processes and, at the same time, improve the efficiency of the process, saving time and providing valuable information to support students in their learning.

\section{LeARning Process Discovery Architecture}

Recently some conceptual architectures characterizing the main components of a learning analytics application have been presented. These architectures describe from a general perspective the relations between the educational data, the data processing algorithms, and the actors involved in learningteaching processes. However, this paper focuses on learning process discovery and, therefore, a framework to characterize this kind of learning analytics applications is necessary. For this reason, we have extended the architecture proposed in [24] by introducing a more precise description of the data 


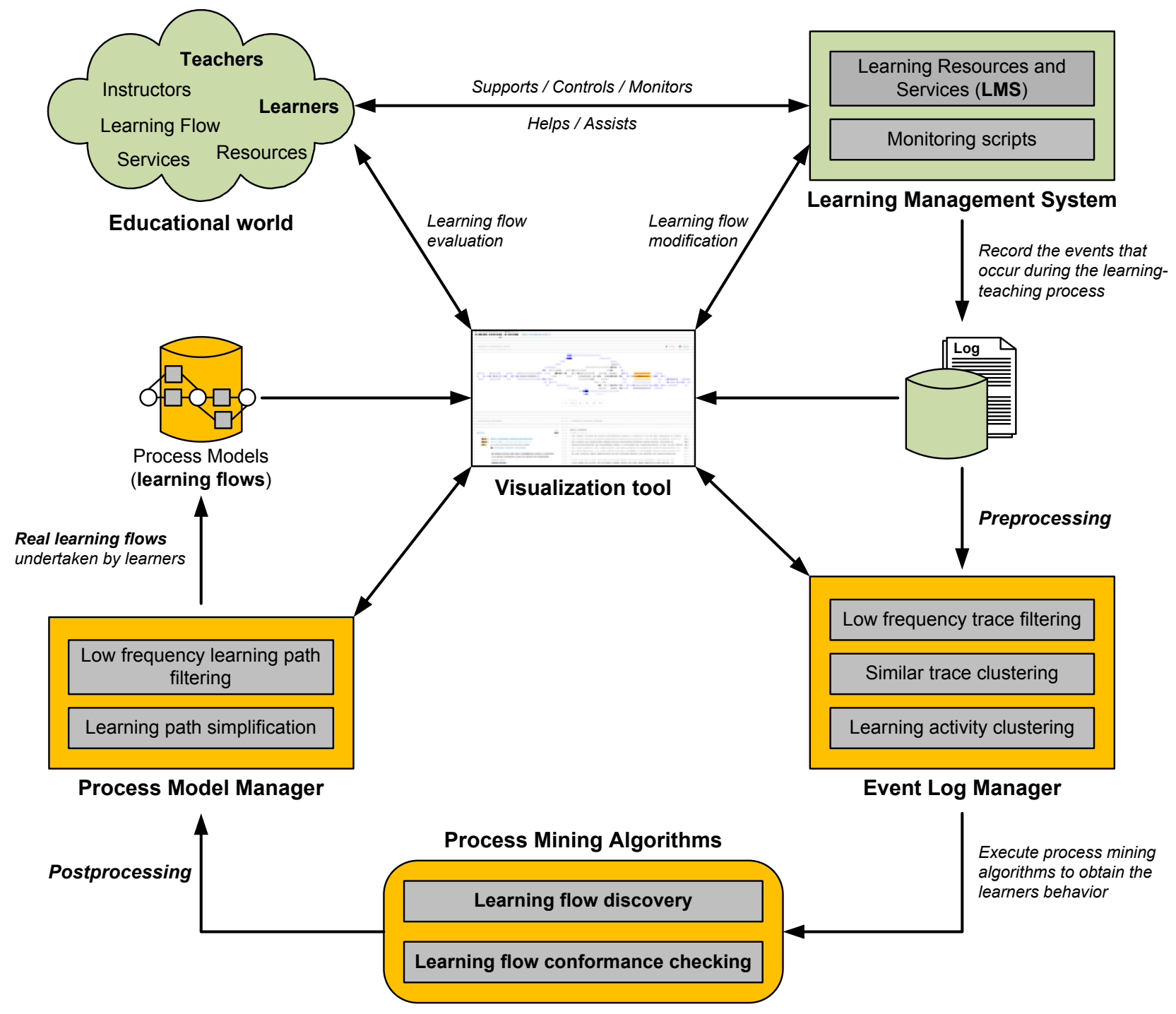

Fig. 1. Architecture for learning process discovery in self-regulated learning.

processing component, i.e., the learning process discovery algorithm, which includes explicitly: pre/post-processing steps; a distinction among the different kind of learning data involved in these applications; and an advanced graphical interface to visualize and evaluate the discovered learning paths. This new conceptual architecture is depicted in Fig. 1.

a) Educational World: Teachers and students are the typical participants in any learning activity. On the one hand, teachers, playing the role of instructors, design the learning processes by following some educational methodology, support the learning activities of the course, and, summarizing, are in charge of supporting student's success. On the other hand, students are the core of the educational world since they undertake the learning activities by using the resources and services available in a personal learning environment.

b) Personal Learning Environments: PLEs provide the means to undertake the learning paths designed by the teachers: students carry out the learning activities planned for a course, accessing to the learning contents and executing the services required to facilitate those activities such as interacting with other students through synchronous tools, looking for information in libraries, and so on. From a process discovery perspective, PLEs detect and register all the relevant events which are related to the undertaking of learning activities by teachers and students such as uploading files, posting blog inputs, answering tests, and so forth. Typically, these events are stored in an event log database that contains two different types of data:

- Metadata. This kind of data describe the context in which an event is generated such as the identifier and type of the learning activity that has been performed, the user that participates in the activity, and the time at which the event has been generated. Note that each student generates a sequence of these metadata, known as trace, and the set of all the traces are the only inputs required by the process discovery algorithms. Fig. 2 shows an extract of the traces stored in ELGG [25] 


\begin{tabular}{|c|c|c|c|c|c|c|c|c|c|c|}
\hline id & object_id & object_class & object_type & object_subtype & event & performed_by_guid & owner_guid & access_id & enabled & time_created \\
\hline 2163 & 47 & ElggUser & user & & login & 47 & 0 & 2 & yes & 1393233212 \\
\hline 2164 & 969 & ElggMetadata & metadata & method & create & 47 & 47 & 2 & yes & 1393233223 \\
\hline 2165 & 230 & ElggWire & object & thewire & create & 47 & 47 & 2 & yes & 1393233223 \\
\hline 2166 & 970 & ElggMetadata & metadata & wire_thread & create & 47 & 47 & 2 & yes & 1393233223 \\
\hline 2167 & 228 & ElggBlog & object & blog & annotate & 98 & 98 & 2 & yes & 1393233239 \\
\hline 2168 & 128 & ElggAnnotation & annotation & generic_comment & create & 47 & 65 & 2 & yes & 1393233239 \\
\hline 2169 & 971 & ElggMetadata & metadata & status & create & 47 & 47 & 2 & yes & 1393233306 \\
\hline 2170 & 972 & ElggMetadata & metadata & comments_on & create & 47 & 47 & 2 & yes & 1393233306 \\
\hline 2171 & 973 & ElggMetadata & metadata & excerpt & create & 47 & 47 & 2 & yes & 1393233306 \\
\hline 2172 & 231 & ElggBlog & object & blog & create & 47 & 47 & 2 & yes & 1393233306 \\
\hline 2173 & 231 & ElggBlog & object & blog & annotate & 47 & 47 & 2 & yes & 1393233331 \\
\hline 2174 & 129 & ElggAnnotation & annotation & likes & create & 34 & 63 & 2 & yes & 1393233331 \\
\hline 2176 & 975 & ElggMetadata & metadata & tags & create & 87 & 87 & 2 & yes & 1393233347 \\
\hline 2177 & 232 & ElggObject & object & bookmarks & create & 87 & 87 & 2 & yes & 1393233347 \\
\hline
\end{tabular}

Fig. 2. Example of event traces registered in ELGG during the subject Educational Technology.

for the subject Educational Technology.

- Learning content. Most of the events are associated with learning content that has been created during the learning activity such as the blog input text, the messages of the forums, and so forth. This kind of data are shown by the graphical interface to facilitate teachers the student's assessment.

c) Event Log Manager: The higher is the number of different traces, the more difficult is to obtain complete, precise and simple descriptions of the learning processes. Typically, this issue is addressed by reducing the complexity of the input space for the process discovery algorithms, i.e., reducing the diversity of the traces available in the event log database. This goal is achieved through a pre-processing component that implements strategies for clustering activities based on teacher's criteria, filtering traces that are not relevant from the point of view of the student's assessment, and clustering traces when several traces are exactly the same.

d) Process Mining Algorithms: This component is the core of the architecture, since it provides the algorithms for process discovery and for evaluating the conformance of a previously designed process. This paper focuses on the discovery of learning processes, and therefore this component implements discovery algorithms whose aim is to obtain the learning process that describes all the learning paths followed by students during a course. The quality of this learning flow is evaluated taking into account the following metrics [26]:

- Completeness, which indicates how much of the behavior observed in the event $\log$ can be reproduced by the discovered learning process. Thus, a learning process is considered as complete when it can reproduce all the events contained in the log database. In order to guarantee feasible and correct student's evaluations, teachers need to access to all the activities performed by students. Therefore, the completeness of discovered learning processes is a hard requirement for the process discovery algorithms.

- Precision, which measures if the discovered learning process is overly general, allowing an additional behavior that is not represented in the log. Thus, a discovered learning process is considered precise when it cannot reproduce events that are not available in the log database. From the point of view of the student's assessment, this kind of learning processes are desirable, but it is not a requirement as hard as completeness: teachers would not visualize the extra behavior since it has not been undertaken by any student.

- Simplicity, which refers to discovered learning processes with the minimal structure that reflects the behavior contained in the log database. A desirable requirement for process discovery algorithms is to obtain simple representations of the discovered learning paths, since it facilitates teachers to understand the student's behavior.

e) Process Model Manager: Discovery algorithms are developed with the aim of guaranteeing the completeness of the discovered learning processes that describe the learning paths of a course. Although these algorithms seek to obtain learning processes that are precise and simple, the main consequence of the requirement about completeness is that discovered learning processes typically have a complex structure. To reduce this complexity, i.e., to get simplest learning processes, it is necessary to introduce a post-processing step that implements strategies for simplifying the graph that describes the learning process and path filtering, where teachers manually remove learning paths to better visualize the learning process. Note that teachers should be able to return to the original model through the graphical interface.

f) Graphical User Interface: This component (Fig. 3) enables teachers to understand the students' behavior through the visualization of the learning paths followed by them during a course ${ }^{1}$. From the point of view of the student's assessment, this visualization has two main issues: how to represent learning processes and how to present the data about the learning activities, including the contents generated by students as part of these activities.

${ }^{1}$ http://tec.citius.usc.es/SoftLearn/ 


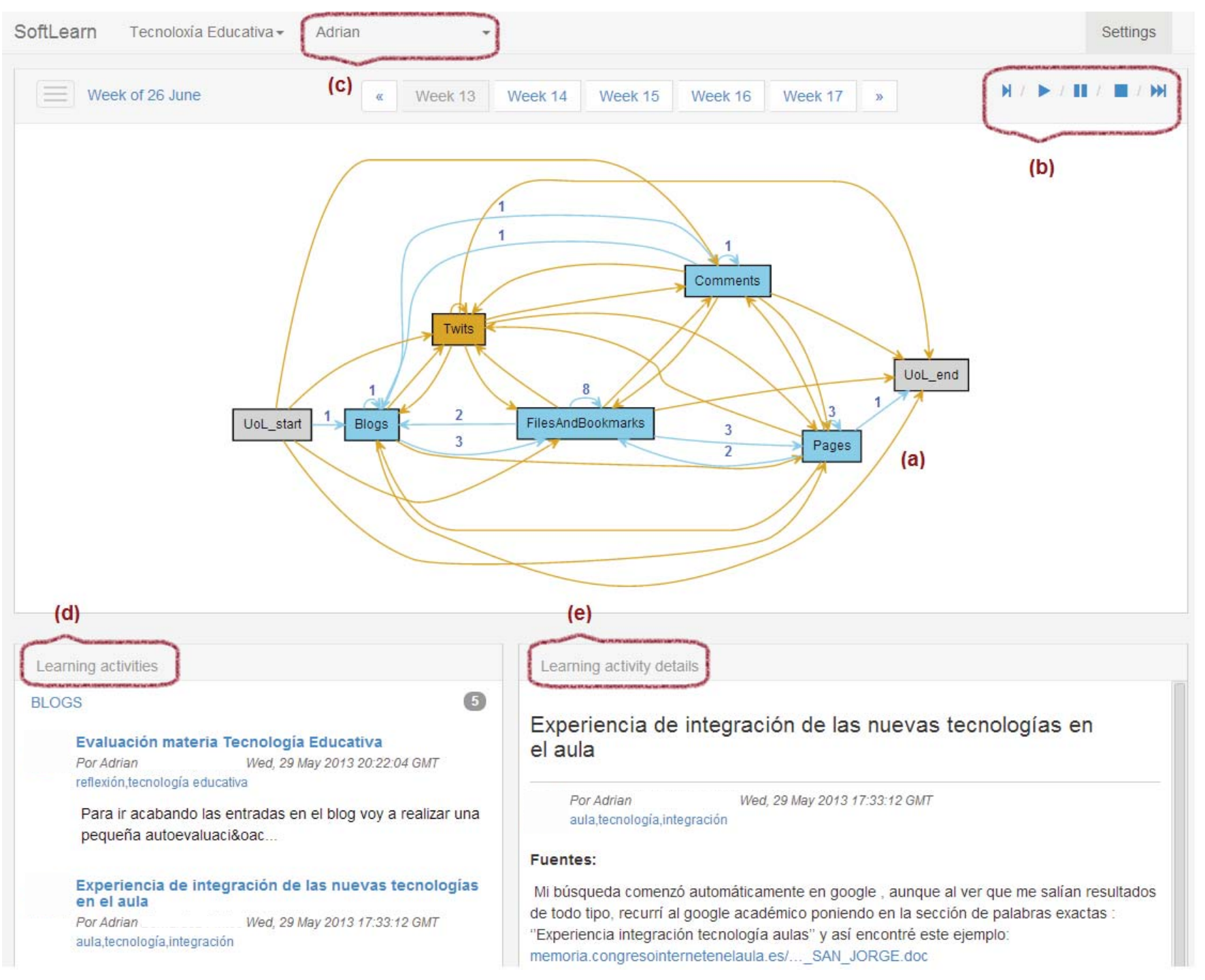

Fig. 3. SoftLearn graphical user interface.

As there is no standard language to visualize learning processes [27] we decided to show the learning processes by means of D/F-graphs [28], which are the output of the learning process discovery algorithm. This kind of graphs represents the dependencies between learning activities by means of arcs, meaning that the source activity of an arc is carried out before the target activity of that arc. These D/F-graphs do not introduce additional control structures, and therefore learning processes are easy to understand. When teachers select a temporal period, such as a week, a month, two months or the entire course, the learning process that describes the behavior for all the students is presented. Then, if the teacher selects a given student (Fig. 3.c), the learning activities performed by that student are highlighted (blue-filled rectangles in Fig. 3.a). Furthermore, in order to facilitate the learning path visualization, the graphical interface incorporates a graph player that allows the execution of the graph in several ways (Fig. 3.b):

- $\quad$ Step by step mode enables users to navigate through the dependency graph by following the execution of each of the learning activities performed by the student. In the graphical interface these activities are filled in blue to be distinguished from the others. This mode is specially designed for the visualization of the learning content associated to the activity which has been activated in the current step.

- Play mode, where the learning path is executed from the beginning to the final activity undertaken by the student. Users can set up the speed at which the activities are highlighted.

- Player actions that enable teachers to stop, resume, and reset the execution of the learning process executed at each moment. These actions can be performed in both step by step and play modes.

The dependency graph does not show any data about the learning activities of the learning process. These data are needed to make an effective student's assessment. Teachers 
can access to the following data by clicking in the activities shown through the dependency graph:

- Metadata, which describe the features of the learning activities, including their timestamp, snippet, creator name, etc. An example of this kind of data is showed in Fig. 3.d.

Learning content, which is related with the learning activity description and with the content generated by the student in the context of the learning activities. Fig. 3.e shows the content of a blog input.

\section{Methodology}

To evaluate the benefits of the SoftLearn tool for students' assessment in self-regulated learning, we have conducted an experiment with the two teachers of the subject Educational Technology of the University of Santiago de Compostela. In this experiment, the 72 students of the subject were divided in two groups of 36 students: the first one was evaluated through the SoftLearn tool, while for evaluating the second one was directly evaluated through the ELGG environment. Fig. 4 shows the ELGG environment where teachers must navigate through web pages (related to blogs, files, pages, etc.) in order to access to the students' e-portfolios. Taking this into account, the evaluation of the SoftLearn tool was made from two different perspectives:

- Pedagogical perspective where teachers evaluate whether the SoftLearn tool allows to improve the students' assessment process and whether it is appropriate for the assessment needed in self-regulated learning. Table II shows the test performed by the teachers for this evaluation.

- Usability perspective where teachers evaluate the SoftLearn tool for testing if it is easy to use and if it provides the information needed for the students' assessment. The test used in this evaluation is the CSUQ test [29], but we have also included a question about the average time needed by teachers to assess students through the SoftLearn tool and the ELGG environment. This parameter is very relevant for the experiment, since one of the main drawbacks of the students' assessment in self-regulated learning is the amount of learning contents to be evaluated.

\section{RESULTS}

The results of the teachers' assessment of the subject set a time saving of $54 \%$. While without the use of the tool the average time to assess the weekly activity for each student was about 2 hours, with SoftLearn this time decreased approximately to 55 minutes. This time savings occurs because the tool eases the reading of the contributions of the students through a better and more accessible overall display. Also, the tool enables to access information that is inaccessible from ELGG. In particular, the information related to both the sequence and timing of the student work, which are key issues in the analysis of the process of self-regulated learning. The sequence expressed in the graph of each student was unknown without the SoftLearn tool, and it allows to understand the differences of the temporal patterns between students with more and less self-regulation [18].
Furthermore, the tool provides information, previously invisible, of the social conditions of learning regulation showing the routes through their peers' blogs, the comments made on them, etc. The sequential characteristics of this type of regulation are specially important because they indicate what actions follow others, and the temporal characteristics show when and how they influence each other [4]. These issues are very relevant, given the social network where the student eportfolio is inserted. The main advantage of the tool is the access to personal and social evidences in a simpler form, given the complexity of assessing all the material produced by students around their personal learning environment.

The tool is very close to the evaluation methodology, as the portfolio is immersed in a social network where the objective is to create and share, allowing both the interaction between the teacher and the student, the student and the content, and the teacher and the content, and the three elements together [30]. In this sense, the tool allows to visualize many of these interactions, and to access to the impact over the class of a student's work in the virtual environment through the analysis of the comments. With respect to usability, the experiments have shown that the system is easy to use, allows to complete the assessment and to obtain the information in an easy way. Moreover, the information is easier to interpret, and the tool has a nice and intuitive interface with an adequate distribution.

The main conclusion of the teachers that used the tool is that they recommend its use. They highlight as its main advantage the time saving, although they also point out that a qualitative assessment also requires, regardless of the use of a tool like SoftLearn, the reading and review of all the evidence [11] of the 72 students of the subject.

\section{CONCLUSIONS}

The research that we propose reflects the needs and realities of education. It starts from our specific experience, seeking to improve and facilitate the assessment as a fundamental step in the process of teaching-learning in complex and diverse spaces like these. In these cases, the teaching approaches incite to create and share, beyond materials or fixed sequences, and the personalization of spaces is taken to the absolute limits.

The learning analytics-based tool presented in this paper facilitates the access to different sections of the PLE of each student in a quicker and more convenient way, contextualizing each task made by the student. Also, it allows to visualize the learning path of the student graphically, starting from the student's knowledge of the subject and heading to the theme of interest, enabling to see the connections between the different nodes at different time slots. Furthermore, the SoftLearn tool allows teachers to improve the student's assessment, reducing significantly the time required to complete this assessment.

\section{ACKNOWLEDGMENT}

This work was supported by the Spanish Ministry of Economy and Competitiveness under the project TIN201122935 and by the European Regional Development Fund (ERDF/FEDER) under the project CN2012/151 of the Galician Ministry of Education. 


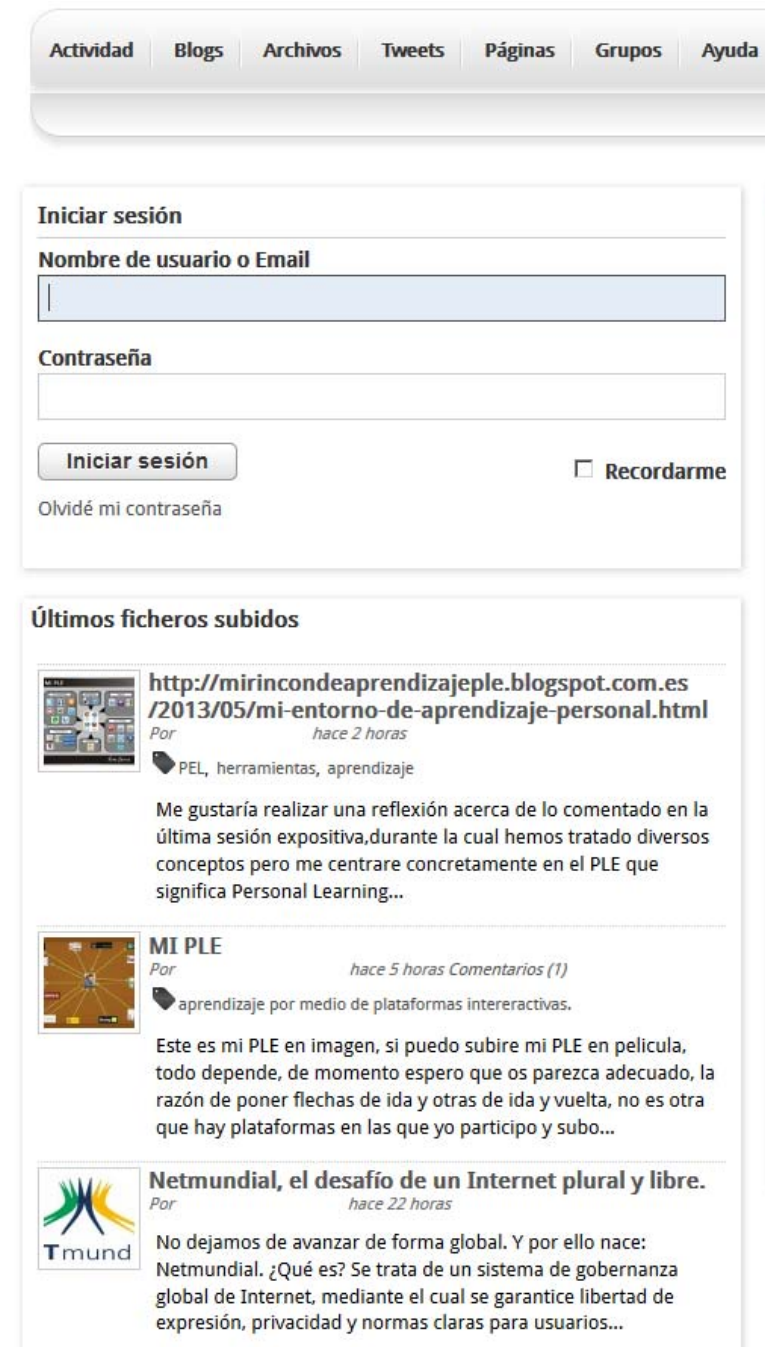

Fig. 4. ELGG environment.

\section{REFERENCES}

[1] R. Azevedo, D. Moos, J. Greene, F. Winters, and J. Cromley, "Why is externally-facilitated regulated learning more effective than selfregulated learning with hypermedia?" Educational Technology Research and Development, vol. 56, no. 1, pp. 45-72, 2008.

[2] P. R. Pintrich, Handbook of self-regulation. San Diego, CA: Academic Press, 2000, ch. The role of goal orientation in self-regulated learning, pp. 452-502.

[3] N. Dabbagh and A. Kitsantas, "Personal learning environments, social media, and self-regulated learning: A natural formula for connecting formal and informal learning," The Internet and higher education, vol. 15 , no. 1 , pp. 3-8, 2012.

[4] I. Molenaar and S. Jrvel, "Sequential and temporal characteristics of self and socially shared regulated learning," Metacognition and Learning, pp. 452-502, 2014.

[5] G. Attwell, "Personal learning environments-the future of elearning?" eLearning Papers, vol. 2, no. 1, pp. 1-8, 2007.

[6] D. R. Garrison, "Cognitive presence for effective asynchronous online learning: The role of reflective inquiry, self-direction and metacognition," Elements of quality online education: Practice and direction, vol. 4, pp. 47-58, 2003.

[7] P. Dillenbourg, "What do you mean by collaborative learning?" Collaborative-learning: Cognitive and computational approaches., pp. 1-19, 1999.
Últimas entradas

\section{Como crear tu PLE \\ Por hace 58 minutos \\ entornos personales de aprendizaje}

Hola de nuevo, leyendo alguna cosilla más sobre este apasionante mundo del PLE, acabo de encontrar algo que me gustaría compartir con vosotros. Aparte de darnos una definición similar a la que Jordi Adell nos mostró en su...

El estudiante en la red

El estudiante en la red
por 3 horas
estudiantes en red, conectivismo, red personal de aprendizaje

Hola a todos, os adjunto a continuación un video sobre "El estudiante en la red" (Networked student) en el que se nos muestra cómo se produce el aprendizaje de los estudiantes del siglo XXI y el papel que van a tener los profesores en...

\section{Palabrajeando. \\ Por hace 3 horas \\ ficcionario, invención, palabras, creatividad}

Palabrajando es un proyecto coordinado por Ramón Besonías, docente en Secundaria y formador en TIC en el IES San José de Badajoz. Con este, colaboran otros profesionales de la educación procedentes de distintas zonas de...

E-learning

Por hace 4 horas Comentarios (1)

e-learning nueva forma proceso enseñanza aprendizaje

En esta entrada, me gustaría tratar el concepto de e-learning, abordado con anterioridad en la clase del pasado martes. A través de su definición, ventajas, inconvenientes... pretendo conocer un campo hasta ahora...
[8] G. Veletsianos and C. C. Navarrete, "Online social networks as formal learning environments: Learner experiences and activities," International Review of Research in Open and Distance Learning, vol. 13, no. 1, pp. 144-166, 2012.

[9] D. Boud, Enhancing learning through self-assessment. Routledge, 1995.

[10] H. C. Barrett, "Strategic questions: What to consider when planning for electronic portfolios," Learning \& Leading with Technology, vol. 26, no. 2, pp. 6-13, 1998.

[11] V. Klenowski, Developing portfolios for learning and assessment: Processes and principles. Psychology Press, 2002.

[12] G. Siemens and D. Gasevic, "Guest Editorial - Learning and Knowledge Analytics," Educational Technology \& Society, vol. 15, no. 3, pp. 1-2, 2012.

[13] S. Knight, S. Buckingham Shum, and K. Littleton, "Collaborative sensemaking in learning analytics," in CSCW (Computer Supported Cooperative Work) and Education Workshop, San Antonio, Texas, USA, 2013.

[14] R. Agrawal and R. Srikant, "Mining sequential patterns," in Proceedings of the 11th International Conference on Data Engineering (ICDE 1995). Los Alamitos, CA, USA: IEEE Computer Society, March 1995, pp. 314.

[15] W. M. P. van der Aalst, Process Mining: Discovery, conformance and enhancement of business processes. Springer-Verlag, 2011. 


\title{
Efficacy
}

Do you think that the tool achieves the defined objectives? Why?

Do you think that the tool improves your work as a teacher? Why?

\author{
Efficiency \\ Can you access the same information as before? \\ Does the tool save further efforts? \\ Does the tool have any impact in the evaluation of your students? In what way? \\ Does the tool change any aspects of your teaching process? In what way?
}

\section{Appropriateness}

Do you think that this kind of tools are necessary? Why?

Do you think that this particular tool meets your evaluation needs? Why?

Does the tool satisfy your evaluation needs? What aspects are not covered?

Is the information provided by the tool consistent with your evaluation methodology? Why?

Would you recommend the use of this tool?

\section{Quality}

Do you think that this tool can improve the use of personal learning environment?

[16] F. Bouchet, J. S. Kinnebrew, G. Biswas, and R. Azevedo, "Identifying students' characteristic learning behaviors in an intelligent tutoring system fostering self-regulated learning," in Proceedings of the 5th International Conference on Educational Data Mining (EDM 2012), K. Yacef, O. R. Zaïane, A. Hershkovitz, M. Yudelson, and J. C. Stamper, Eds., Chania, Greece, 2012, pp. 65-72.

[17] D. Perera, J. Kay, I. Koprinska, and O. R. Yacef, Kalina andZaïane, "Clustering and sequential pattern mining of online collaborative learning data," IEEE Transactions on Knowledge and Data Engineering, vol. 21, no. 6, pp. 759-772, 2009.

[18] M. Bannert, P. Reimann, and C. Sonnenberg, "Process mining techniques for analysing patterns and strategies in students' self-regulated learning," Metacognition and Learning, 2014, dOI: 10.1007/s11409013-9107-6.

[19] C. Schoor and M. Bannert, "Exploring regulatory processes during a computer-supported collaborative learning task using process mining," Computers in Human Behavior, vol. 28, no. 4, pp. 1321-1331, July 2012.

[20] R. Bergenthum, J. Desel, A. Harrer, and S. Mauser, Transactions on Petri Nets and Other Models of Concurrency $V$, ser. Lecture Notes in Computer Science. Berlin, Heidelberg: Springer-Verlag, 2012, vol. 6900, ch. Modeling and mining of learnflows, pp. 22-50.

[21] R. A. Calvo, S. T. O'Rourke, J. Jones, K. Yacef, and P. Reimann, "Collaborative writing support tools on the cloud," IEEE Transactions on Learning Technologies, vol. 4, no. 1, pp. 88-97, Jan.-March 2011, dOI: 10.1109/TLT.2010.43.

[22] M. Pechenizkiy, N. Trcka, E. Vasilyeva, W. M. P. van der Aalst, and P. de Bra, "Process mining online assessment data," in Proceedings of the 2nd International Conference on Educational Data Mining (EDM 2009), T. Barnes, M. C. Desmarais, C. Romero, and S. Ventura, Eds., Córdoba, Spain, 2009, pp. 279-288.

[23] R. Ellis and P. Goodyear, Students' experiences of e-learning in higher education. Routledge, 2010.

[24] N. Trcka, M. Pechenizkiy, and W. P. M. van der Aalst, Handbook of Educational Data Mining, ser. Data Mining and Knowledge Discovery. Boca Raton, FL, USA: Chapman and Hall/CRC, 2011, ch. Process mining from educational data, pp. 123-142.

[25] C. Costello, Elgg 1.8 Social Networking. Packt Publishing, 2012.
[26] A. Rozinat, A. K. Alves de Medeiros, C. W. Günther, A. J. M. M. Weijters, and W. M. P. van der Aalst, "The need for a process mining evaluation framework in research and practice," in Business Process Management Workshops, ser. Lecture Notes in Computer Science, A. H. M. ter Hofstede, B. Benatallah, and H.-Y. Paik, Eds., vol. 4928. Springer, 2007, pp. 84-89.

[27] M. C. Rodríguez, M. Derntl, and L. Botturi, "Visual instructional design languages,” Journal of Visual Languages and Computing, vol. 21, no. 6, pp. 311-312, 2010.

[28] A. J. M. M. Weijters, W. M. P. van der Aalst, and A. K. A. De Medeiros, "Process mining with the heuristics miner-algorithm," Technische Universiteit Eindhoven, Tech. Rep. WP, vol. 166, 2006.

[29] J. R. Lewis, "Ibm computer usability satisfaction questionnaires: psychometric evaluation and instructions for use," International Journal of Human-Computer Interaction, vol. 7, no. 1, pp. 57-78, 1995.

[30] T. D. Anderson and R. Garrison, Distance learners in higher education. Madison, WI: Atwood Publishing., 1998, ch. Learning in a networked world: New roles and responsibilities, pp. 97-112. 